\title{
La recepción de la hermenéutica en España
}

\author{
ANDRÉS ORTIZ-OSÉS \\ Universidad de Deusto
}

\section{La Europa hemenéutica}

La actual filosofía hermenéutica - también llamada neohermenéutica- se funda en 1960 con la obra de corte neoclásico Verdad y método de Hans-Georg Gadamcr, escrita a sus sesenta años de edad. La obra representa una inflexión linguístico-interpretativa en el filosofar, que se reclama especialmente de Schleiermacher, Dilthey y Heidegger. Su tesis acaso más característica es la ontologicidad del lenguaje, segun la cual la lingüisticidad (Sprachlichkeit) es la estructura profunda de la realidad toda. Con ello la hermenéutica entra en el giro lingüístico de la filosofía contemporánea, pero con un matiz diferencial: pues la lingüisticidad de lo real —el lenguaje como médium del sentido- trasciende no sólo la visión analitica del lenguaje como "medio" semántico del significado, sino también la revisión estructuralista del lenguaje lingüístico o "lengua» paradigmática de explicación sintáctica; por otra parte, la hermenéutica resituaba el lengraje ontológico y su lingüisticidad omnímoda dialecticamente, es decir, como diálogo trascendental del hombre en su mundo (experiencia), superando así la clásica posición marxista que solía colocar el lenguaje en la supraestructura ideológica como comunicación de ideas.

La hermenéutica clásica (gadameriana) representaba una transposición de las diferentes corrientes reduccionistas $y$, muy especialmente, de la tradición escolástica casi desde dentro, es decir, a partir de Platón y, en menor medida, de Aristóteles (tarea facilitada por la feno- menología trascendental husserliana). Pero, sin duda, será Heidegger el gran mentor de Gadamer y su hermenéutica, especialmente el tercero y último Heidegger, el que publica en 1959 De camino hacia el lenguaje (o como se han empeñado en traducir al español: De camino al habla). Con el élan heideggeriano, la hermenéutica se convierte en una nueva Filosofía primera, lo que Gadamer expresa con el concepto de "universalidad" del planteamiento hermenéutico del mundo. Por otra parte, el espiritu teológico-protestántico alemán se deja sentir a través de Verdad y método, convertido en la nueva biblia de la hermenéutica; se trata del libre espiritu protestántico de interpretación, capaz de recoger no sólo la tradición ilustrada sino la romántica, obtenicndo socráticamente el lenguaje vivo (oral) la preminencia sobre el logos estático.'

Pero en 1960 España no pertenecía a la Europa hermenéutica sino a una oscura tradición antihermenéutica. La España de los Traductores de Toledo y de las tres culturas sufría una Escolástica asfixiante, anterior a la apertura del Concilio Vaticano II, al intercambio de emigrantes por turistas y a la democracia. La palabra shermenéutica» obtenía aún un tufo eclesiástico cuasi-dogmáti$\mathrm{co}$, tal y como aparece en la definición que le otorgaba el Diccionario de la Real Academia: warte de interpretar textos para fijar su verdadero sentido".2 Ignora esta definición que ningún arte "fija" nada, y menos el arte de la faena hermenéutica, des-fijadora de toda verdad dogmática en nombre del sentido. Así que, cuando poco a poco se comenzó a ha- 
blar laicamente de hermenéutica, ésta reobtuvo una connotación simbolista o alejandrina que contrastaba con la literal tendencia antioguena propia de nuestro pobre realismo hirsuto. En un tal contexto constreñido, la incipiente hermenéutica era vista como "idealistan, sin la benévola audiencia que este vocablo tiene en Alemania, por escolásticos, marxistas, analíticos y estructuralistas.

Pero quizás fue bueno para la hermenéutica que no fuera una ciencia (compacta) sino un arte (abierto): una actitud o talante ante las cosas, un blick y un élan. Acaso por ello la hermenéutica se infiltra en nuestro país difusamente, y no a través de camarillas cerradas, a raíz de la publicación de Verdad y método en la colección "Hermeneia" de la editorial Sígueme de Salamanca, tras personal contacto con su autor. De todas formas, cabe destacar junto a esa "difusion» algunos nombres de hermeneutas mayores (junto a otros menores), que encarnan una recepción más específica entre nosotros: tal es el caso de Luis Alonso Schökel en teología bíblica (junto al cual podríamos colocar al hermeneuta de las religiones Raimon $\mathrm{Pa}-$ nikkar), Emilio Lledó en filosofía pura y un servidor (con la venia) en filosofía impura o antroposimbólica, en cuyo ámbito me gustaría concitar a JuanEduardo Cirlot. Hay muchos esforzados de la res hermeneutica, despertados no sólo por Gadamer sino también por P. Ricocur, así como por la hermenéutica crítica de Apel y Habermas o, finalmente, por la continuación mitocrítica de G. Durand, la posmodema de G. Vattimo o la mitológica de $M$. Frank.

Repasemos brevemente el panorama.

\section{La España hermenéutica}

La hermenéutica en España tendría a mi entender un claro precursor en mestro Ortega y Gasset, que no en vano remitió a Dilthey para fundar su razón viviente o vital y su perspectivismo. En su comentario al Banquete de Platón, podemos colegir una visión de la lectura bien hermenéutica: "leer es abandonar nuestra pasividad frente al texto y construirnos laboriosamente toda la realidad mental no dicha en el, pero que es imprescindible para entenderlo». ${ }^{3}$

Ahora bien, Ortega es un prehermeneuta (lo que se nota en su énfasis sobre la realidad mental, a pesar de su raciovitalismo). Para poder hablar de hermenéutica española stricto serusu hay que referirse a la teología biblica predicada/practicada por Luis Alonso Schökel en su cátedra de exégesis en el Instituto Bíblico de Roma; de esta forma recalamos la hermenéutica filosófica en su origen teológico, siguiendo el planteamiento del viejo $R$. Lull sobre que la teología es la madre y el espejo donde se refracta la filosofía. Entre sus obras destacamos a nuestro propósito: Hemenéutica de la palabra, El misterio de la palabra, La palabra inspirada.

El prof. Alonso Schökel se ha inspirado no sólo en Gadamer, sino también en Ricoeur (entre otros). para su Hermenéutica bíblica: este rabino cristiano reentiende la hermenéutica como targum (paráfrasis) y midrash (recreación), pero poniendo mayor énfasis en la amplificación propia del símbolo, que en el quid-pro-quo propio de la metafora. Mientras la metáfora se pone en vez de algo, el símbolo traspone a partir o a raiz, de algo, fundando un plus de significación que desborda al mero significado.

Podemos considerar a Alonso Schökel, con un pie en Europa y el otro en España, como perteneciente al trasfondo hermenéutico español. Algo parejo cabría afirmar de Raimon Panikkar, hermeneuta de las religiones, situado entre Espana, Estados Unidos y la India. ${ }^{4}$

El fondo hermenéutico estaría representado, laicamente, por Emilio Lledó, 
discípulo directo de Gadamer en Heidelberg y autor de las obras Filosofía y lenguaje, La filosofia, hoy y La expresión. filosófica. Es cierto que Lledó hereda de Gadamer más bien una postura protohermenéutica, anclándose en una filosofía del logos como razón democrática compartida, que da cuenta de la integridad hermenéutica. Por ello representa sobre todo la hermenéutica ilustrada, racional y crítica, aquella que hunde sus raíces en la Atenas clásica. He aquí que el logos del lenguaje llevaría a cabo, para nuestro autor, tanto la distinción del hombre respecto a su indistinción (animal) como su posterior revinculación con la naturaleza articulada. $O$ el lenguaje como estructurador de una realidad diferenciada por el hombre: no extrañará, en este contexto, su acogimiento a la sentencia de $C$. Riba sobre que ulas palabras se nombran para entendemos, y no para entenderlas, pues que son el comienzo, una señal del sentido». Con ello Lledó fundaría una especie de semántica pragmática (hermenéutica).

En su obra Filosofia y lenguaje un aforismo resume bien el pensamiento hermenéutico emancipador de nuestro autor: "El aire del pensamiento es el lenguaje». Pareciera el presagio de la posterior hermenéutica etérea tipo posmoderno, pero Lledó es un hermeneuta académico y concienzudo, que reentiende el aire no deletéreamente sino como "resistencias que precisamente posibilita el pensamiento. ${ }^{\text {S }}$ Estaríamos en el campo de Anaxímenes, para el cual todo procede del aire y su rarefacción (desplazamiento y condensación), pudiéndose reinterpretar como fluido "trópico" o metafórico-simbólico. El lenguaje, como elemento trópico del pensamiento, resultaría entonces, como en Anaxímenes, el alma que uanima» la realidad dotándola de vida.

Así, el lenguaje adquiere cierta diafa- nidad o transparencia, siquiera vidriosa, que sin embargo se resquebraja en otras tradiciones más románticas ilustradas, más míticas que lógicas, más irracionales que racionales, más simbólicas que semióticas. $Y$ ello porque tras el logos clásico (indoeuropeo) subyace el $m y$ thos preindoeuropeo (protomediterráneo). puesto que tras la Atenas clásica está la Creta preclásica, y tras el lenguaje linguístico (estructura de la convivencia) yace el lenguaje imaginal y su vivencia. ${ }^{\circ}$ Es aqui donde aparece una torsión hermeneutica que replantea el logos de lo real a partir del sentido axiológico. Pero con ello me estoy acercando a una her. menéutica simbólica.

Mas antes de pasar a la propia posición al respecto, quisiera rendir breve homenaje a Juan-Eduardo Cirlot, crítico de artc, poeta surreal y autor del excelente Diccionario de símbolos. En este úlimo, el autor define la interpretación a lo Jung: como una amplificación que lleva a cabo el símbolo. El símbolo, que unifica sin confundir los contrarios, es la comunicación con lo incomunicable, posibilitando la circulación de los diferentes niveles de la realidad. ${ }^{7}$

Traemos a colación la hermenéutica simbolica de Cirlot, no sólo como engarce con la actual hermenéutica simbólica, sino como exponente de la exigua tradición mitosimbólica española, que encontraría en Ángel Álvarez de Miranda su versión mitocrítica. ${ }^{8}$ Esta corriente simbólica -romántica- de la hermenéutica obticne en el propio Gadamer un lugar propio: Verdad y método concita, en efecto, al viejo mitosimbólogo F. Creuzer, el inspirador de Bachofen, Nictzsche y el Círculo Eranos, pudiéndose considerar como el precursor de una interpretación imaginal de lo real vivido: de donde su concepción del lenguaje simbólico como mediación tensional de los opuestos (la imagen y el sentido).9 


\section{La hemenéutica simbólica}

Andrés Ortiz-Osés ha realizado una hermenéulica que, partiendo del inicial planteamiento gadameriano y su continuación crítica, concluira -a través de E. Cassirer- cercano al Círculo Eranos constituido en torno a Jung, Kèrènyi, E. Neumann, A. Portmann, G. Durand y J. Hillman. El autor reinterpreta el Ser a raiz de la protovivencia (mythos) del hombre en su mundo: de esta guisa se realiza el trasvase del logos clásico (patriarcal) al mythos preclásico (matriarcal), a cuya estructura simbólica pertenece el trasfondo mitológico vasco. Ahora bien, como se trata de una hermeneutica abigarrada, podríanse diferenciar tres etapas o niveles en su producción:

1. ${ }^{2}$ etapa: Constitución de una hemenétitica filosófica que parte de Gadamer y se confronta con el estructuralismo, Habermas y la tradición romántica (Bachofen, Nietzsche, Heidegger). La linguiicidad del ser se reinterpreta aquí -a traves del viejo Amor Ruibal - como relacionalidad, accediendo a una hermenéutica de la implicación, es decir, a un pensamiento reversivo basado en la dualéctica de los contrarios coimplicados. El texto que refleja esta atmósfera es $L a$ rueva filosofía hermenéutica.

2. "etapa: Constitución de una hemenéutica antropológica al realizar el paso de la teoria a la praxis (aplicación), especialmente en la antropología vasca. Destacaríamos las obras Antropología simbólica vasca y El matriarcalismo vasco. El «mito» vasco, recopilado por J.M. Barandiarán, es interpretado como remitente al trasfondo preindoeuropeo de signo matriarcal-naturalista y comunalista, entrando en litigio con el logos imperante de signo patriarcal-racionalista e individualista. El autor trata de mediar entre matriarcalismo y patriarcalismo: en un fratriarcado androginico que se reclama de Hemes, el dios que media el inframundo ctónico y el supramundo celeste-racional (olímpico).

3. ${ }^{\circ}$ etapa: Constitución de una hernzenéutica simbólica o imaginal, en la cual el «inconsciente colectivo" es reinterpretado como «imaginario arquetípico", de signo ontológico, trascendental o radical. Este imaginario (mitosimbólico) representa la gran mediación de la cultura, por lo cual toda fundamentación resulta ser imaginaria. De este modo, la ontologicidad del lenguaje en Gadamer se reconvierte ahora en la ontologicidad del lenguaje imaginal, ya que la realidad se constituye como con-figuración energética, y se instituye como refiguración humana. Las obras características de este período serian Mitología cultural y Iung: Arquetipos y sentido. ${ }^{10}$

Uno piensa que la hermenéutica es teoria y praxis (aplicación) y que, por tanto, la interpretación debe encamarse para poder lograr la asunción y mediación de lo real. Cierto, la especificidad de la hermenéutica filosófica estará siempre, a nuestro entender, en «reconectar" la realidad dada o típica (tipicidad) en su arquetipicidad de fondo, ya que el sentido emerge precisamente en esa conexión o coimplicidad simbolica (casi podría hablarse de la reconversión de la realidad dada en realidad-dadá o dadaísta, es decir, simbólica). Ahora bien, esa arquetipicidad de fondo albergada en el imaginario radical o trascendental, no debe ser pensada logocéntricamente (monoteísticamente) sino plural y politeístamente: pues los arquetipos son los dioses, démones o destinos de nuestra vida en su con-figuración o constelación de sentido (y sinsentido). Por ello, la hermenéutica es plural, abierta y recreadora, proyectiva o imagínica, posibilitando una con-jugación de interpretaciones diferenciadas en torno a reincidentes motivos mitosimbólicos fundamentales.

Este excurso viene a cuento porque 
sería injusto no concitar aqui, siquiera sesgadamente, las diferentes hermenéuticas aplicadas que, desde sus respectivos horizontes de lenguaje, pueblan nuestro mundo cultural. A veces se trata de habitudes hermenéuticas profundas, como en el caso de María Zambrano, Aranguren y Rof Carballo; otras veces se trata de acercamientos metodológicos de tipo hermenéutico, como en el caso de L. Cencillo y A. López Quintás. En ocasiones la actitud hermenéutica configura la reflexión del campo específico: psicológico en el caso de C. Castilla del Pino, antropológico en el de C. Lisón Tolosana, semiótico en el de X. Rubert de Ventós, crítico en el de M. Ballestero, literario en C. G. Gual y José Jiménez, sociocultural en el caso de R. Buckley y A. Nogueira.

Mención aparte nos merece Eugenio Trías, nuestro mejor filósofo actual, cuya obra se caracteriza por una exquisita sensibilidad hermenéutica. En su última obra - La aventura filosófica- el autor nos ofrece una "versión" del Ser como gozne, bisagra o limite-frontera entre la cosa (hermética) y el logos (hermenéutico) -especie de barra o guión que une-y-escinde los contrarios. ${ }^{11}$

\section{Conchusión: Poshemeneutica}

La recepción de la hermenéutica en España puede aparecer, desde fuera, como una decepción: pareciera que el logos hermenéutico - la hermeneia, embajada o "mitencias de Hermes- se hubiera encarnado entre nosotros, pero que los suyos no la hubieran recibido (bien). $Y$, sin embargo, la recepción es real, sobre todo a través de la relectura posmoderna de G. Vattimo entre nosotros, replanteando la cuestión del nihilismo y la (des)fundamentación. Ello ha servido para redefinir al ser como un lenguaje: lenguaje apoetante» o potenciante, voluntad de potencia irreductible a la voluntad de poder. ${ }^{12}$
La hermenéutica posmoderna ha puesto en crisis la fundamentación de la realidad omnímoda en el ser-logos de la metafísica clásica occidental, la cual es una hermenéutica ontonacionalista, nuestra mitologfa indoeuropea, y no la versión absoluta de la realidad: en su casilla vacía se yergue ahora un lenguaje movedizo y un sentido flotante. Ahora bien, una cosa es fundar la realidad en el ser-logos clásico, y otra desfundamentarla definitivamente en nombre de un lenguaje cuasi nihilista. Entre la clásica fundamentación ontorracionalista y la desfundamentación posmoderna, cabe una fundamentación antifundamentalista: la fundamentación imaginaria.

Todo fundamento es imaginario: el sentido se sitúa ahora entre la realidad y la idealidad, en el ámbito de un imaginario con-figurativo y re-figurativo de una surrealidad vivida. El sentido, en efecto, es el abma de las cosas, y el alma habita el espectro imaginal entre el espíritu y el cuerpo, la conciencia y el inconsciente, lo racional y lo irracional: lugar relacional de la articulación del ser (anima quodammodo omnia), ámbito del apalabramicnto radical con un destino convertido en destinación apropiada, espacio de la interpretación implicativa o coimplice. ${ }^{13}$

Vayamos concluyendo. Pienso que la hermenéutica, tanto en España como fuera, constituye ya un movimiento implicado en el filosofar contemporáneo. Yo la entendería como una actitud fundamental -fundacional-- de la filosofía, acaso como su consciencia crítico/criptica, la cual nunca debería convertirse en doctrina cerrada, puesto que su misión es precisamente abrir los textos a su textura o urdimbre latente, así pues reconectarlos con el sentido, y no abandonarlos a su letra muerta. Con ello la hermenéutica abriría la vía a una nueva ilustración romántica, en la que el logos díga al mythos y la razón al cora- 
zón. O la hermeneutica como modo implicado del filosofar, y no como moda de la filosofía (so pena de acabar modicamente).

Podríamos caracterizar la filosofía prehermenétutica como basada en la list der Vermunft o listeza de la razón, mientras que la filosofía hermenéutica se basa en la Lust der Sprache o goce del lenguaje.
Una filosofia poshemenétutica se proyectaría en el Los des Sinnbildes: en el destino de la imagen (simbolica) del sentido. Ahora bien, el destino como destinación (apropiada) es el propio sentido: es el lote que nos cae en stuerte como arquetipicidad o coimplicidad ontológica. Así traduciría, finalmente, la lingüicidad del ser: como la religación del sentido.

\section{NOTAS}

1. Gadamer, H.G.: Verdad y mérodo, Salamanca, Sigucme, 1977, passim especialmente Platón.

2. Real Academia Española, Diccionario martual e ilustrado de la lengua española, Madrid. EspasaCalpe, 1927, voz aHermenéutica».

3. Ortega y Gasset, J.: Obras Completas, vol. 9, Madrid, Rcvista de Occidente, 1965, p. 752.

4. Sobre R. Panikkar, vease la Revista Anthropos, n. $53-54$ (1985).

5. Lledó, E.: Filosofía y lenguaje, Barcelona, Ariel, 1970, p. 115 .

6. Consúltese especialmente F. Nietzsche (Vordad y mentira en sentido extramoral).

7. Cirlot, J.E.: Diccionario de sinbolos, 5:" edición, Barcelona, Labor, 1982, Intraducción general.

8. Alvarez de Miranda, A.: Obras, 2 vols. Madrid, Eds. Cultura Hispanica, 1959.

9. Vease Gadamer, H.G.: Wahreit und Methode, Tubinga, Mohr, 1960, p. 73 ss,

10. La mejor sintesis sistemática del autor es Metafisica det sentido, Universidad Deusto, 1989.
Puede consultarse sobre todo ello la Revista Anthropos, número monográfico sobre Ilermeneutica simbolica, n." 57 (1985).

11. Trias, Eugenio: La aventura filosofica, Madrid, Mondadori, 1988, pp. 328-334.

12. Puede consultarse G. Vattimo (y otros), En tomo a la posnodentidad, Barcelona, Anthropos, 1990.

13. El lenguaje inaginal se sitúa entre lo real-có sico (reificado) y lo ideal-eidético (etéreo): por ello su simbologia es actatica, ya que el agua es el simbolo del simbolo (geminal). Como ya sabía Heradito, de la imago (acuatica) está hecha el abma (de las cosas): fragm. 36. Véase sobre todo ello mi Epilogo a Waldo Ross, Nuestro imaginario cultural, Barcelona, Anthropos, 1992. Curiosamente, en Heráclito (id.) el alma procede del agua (imaginal) pero no se reduce a ella (so pena de morir): ello simboliza que la imago (acuática) remite al alna como urdimbre arquetípica del sentido. La reducción contraria (del alma a imagen) es un "gozo mortufero (n: 77 ).

\section{BIBLIOGRAFIA BÁSICA INTERPRETADA}

\section{Hemenétutica continental}

Bachofen, J.I.: Mitologia arraica y derecho materno, Barcelona, Anthropos, 1988. [El cofundador de la hermeneutica mitosimbólica -con F. Creuzer-, inspirador de Nietzsche y Eranos.]

Durand, G.: La maginacion simbolica, Buenos Aines, Amorrortu, 1971. [E] texto bésico de la mitocrtica, en la linea de la hermenética simbólica de Eranos, especialmente Jung, $\boldsymbol{H}$. Corbin, M. Eliade.]

Gadamer, H.G.: Verdad y método, Salamanca, Sigueme, 1977. [I a obra clásica de la hemenéutica filosófica. Entre los neohermeneutas podemos citar a P. Ricoeur, K.O. Apel, J. Habermas, G. Vattimo, M. Frank.]

Juno, C.G.: Arquetipos y sentido, Universidad de Deusto, 1988. [La hermenéutica arquetipal de Jung, actualizada y reinterpretada.]

MaxR, F.K.: La mitologta occidental, Barcelona,
Anthropos, 1989. [Estudio simbolico del trasfondo mitológico preindoeuropeo, en la línea de Bachofen y Eranos.]

\section{Hermentutica perinsular}

Cralot, I.E: Diccionario de simbolos, Barcelona, Labor, 1982. [Simbología de inspiración hementica: Jung, Bachofen, Eranos, tradición alquimica y el esoterismo.]

Garioalza Luis: La interpretacion de los simbolos, Barcelona, Anthropos, 1990. [Estudio sobre Gadamer, Cassirer y $G$. Durand.]

Hemenéutica simbolica. Monográfico de la Revista Anthropos n. 57 (1985).

Luedo, E.: Filosofia y lenguaje, Barcelona, Ariel 1970. [La hermeneutica como filosofía del logos de] lenguaje.]

Macerras, M. y Trebolle, J.: La hemenética con- 
temporánea, Madrid, Cincel, 1990. [Introducción a conceptos y autores.]

ORnz-Oses, A.: Metafisica del sentido, Bilbao, Universidad de Deusto, 1989. CCalificada por E. Trías -El País (10-II-1991) - como una warqueología del sentido». Metafísica simbolica poseranosiana.]

Ross, W. (ed): Nuestro imaginario cultural, Barcelona, Anthropos, 1992. (Eplogo sobre la hermeneutica imaginal.)

ScHokel, Luis Alonso: Hemenéutica de la palabra, Madrid, Cristiandad, 1987. [Tratado de hemenéutica bíbica (católica).]
Sobre hemenéutica. Monográfico de Estudios filosoficos, 95 (1985).

VATnMo, G. (ed.): En tomo a la posmodemidad, Barcelona, Anthropos, 1990. [Autores varios sobre la poshermencutica.]

Veruat, A. (ed.): El retomo de Hemes, Barcelona, Anthropos, 1989. [Simposio sobre Initocritica y herneneutica simbolica.]

VV.AA.: Poetica del imaginorio. Simposio semiotico-hemenétutico-mitocrtico, Universidad de Sevilla, Facultad CC. Información, 1990.

\title{
La identidad en conflicto
}

\author{
CARLOS PEREDA \\ UNAM, México
}

Algunas preguntas de interés en relación con la identidad de los seres humanos se formulan interrogando "cquièn soy yo?", "¿quién eres tú?". ¿Qué decir de estas preguntas, además de que son prestigiosas?

En primer lugar, se trata de preguntas referenciales cuyas respuestas poseen la forma general "yo soy un $x$, wtú eres un $x \%$. Responder es satisfacer la variable introduciendo diversos conceptos biológicos, sociales, psicológicos. Por ejemplo, algunas respuestas son: yo soy un hombre de tez blanca, un esposo, un padre, un profesor de filosofía de la UNAM, un ciudadano de clase media, un habitante de la ciudad de México, un melancólico, un aprensivo... Las listas de referencias, tanto las que corresponden al yo como al tú, son ilimitadas y pueden incluir una gran variedad de las clasificaciones biologicas, sociales y psicológicas que pone a disposición una tradición. Sin embargo, esas respuestas pocas veces se dan como predicaciones aisladas a la manera de "yo soy un hombre de tez blanca", "un esposon, "um padre*... Cuando se nos pregunta o preguntamos quién soy yo, quién eres tú, la respuesta tiende a procurar que las diversas predicaciones se articulen en narrativas. Ni yo ni tú somos acumulaciones desordenadas de predicaciones biológicas, sociales, psicológicas. Cada uno de nosotros es una narrativa singularísima que va totalizando de cierta manera las varias atribuciones. Yo soy..., tú eres... una existencia, una historia concreta. $A$ esas narrativas particulares, a esas historias específicas que yo soy y que tú eres las llamo uidentidad material" de los seres humanos. A las narativas que conforman esta identidad se las puede distinguír, a su vez, en dos grandes grupos: aquellas con predicaciones que atañen a los seres humanos en tanto individuos - Pedro vivió en Tampi$c 0$, Pedro es un padre...- o identidad individual; y aquellas otras con predicaciones que lo ubican en tanto miembro de un grupo significativo - los negros, las mujeres, los homosexuales, los latinoamericanos... - o identidad grupal: la identidad grupal se articula a partir de experiencias con ciertos prototipos socia- 